\title{
Polymers from Dimethyl Substituted Hydroxyphenyl Phthalazinone
}

\author{
LianZhou ChEN, Xigao JiAN, ${ }^{\dagger}$ and Xiuling ZHU \\ Department of Polymer Science, College of Chemical Engineering, Dalian University of Technology, \\ Dalian 116012, People's Republic of China
}

(Received September 16, 1998)

KEY WORDS Poly(aryl ether)s / Phthalazinone / Dihalid / Preparation / Solubility /

Poly(arylene ether)s, are the most important high performance thermoplastics with high thermooxidative stability and glass transition temperature. They have found many applications in the electronics and aerospace industries due to their excellent electrical, mechanical and thermal properties. ${ }^{1-4}$ These polymers are especially desirable because they are economically accessible by both nucleophilic and electrophilic routes. ${ }^{5-7}$ Much effort has been expended toward the synthesis of the polymers. However, these polymers have limited use because of their poor solubility or not very good thermal properties.

Considerable attention also has been devoted to these polymers to improve the processability. The development of good solubility of high-performance polymers would undoubtedly broaden the future applications of these excellent materials. In recent years, poly(aryl ether ketone)s have been prepared containing 2,6-naphthalene or 1,5-naphthalene units. Ohno ${ }^{8}$ and Hergenrother ${ }^{7}$ reported that poly(aryl ether ketone)s containing naphthalene moieties in the main chain possess higher $T_{\mathrm{g}} \mathrm{s}$, but the solubility in organic solvents is not very good. Polymers have been synthesized from phenolphthalein, which have higher $T_{\mathrm{g}} \mathrm{s}$ and better solubility because the molecule is not symmetrical and the polymers are amorphous. ${ }^{9,10}$ But problems often arise in the synthesis of these polymers as well as in the processing of the materials because of reactions involving the lactone ring. Therefore, a great deal of effort has made for improving the solubility of these polymers. ${ }^{7-18}$ These efforts include: (1) introducing 2,6-naphthalene or 1,5naphthalene units. (2) replacing symmetrical aromatic rings by the unsymmetrical ones, which leads to a reduction incrystallinity. (3) incorporating alkyl or alkoxy substituent aromatic units along the polymer backbone to minimize crystallization. (4) introducing the heterocyclic ring moities.

Recently, $\mathrm{Hay}^{18}$ reported the synthesis of polymers from 1,2-dihydro-4-dihydroxylphenyl-1(2H)-phthalazinone (1) and bis(4-fluorophenyl)sulfone (2) (Scheme 1). The paper described the phthalazinone NH groups behave like $\mathrm{OH}$ groups. This is the first report polymerization marked by an aza-nitrogen-anion displacement of fluorine from an activated aryl fluoride. The poly(aryl ether phthalazine)s with the $\mathrm{N}-\mathrm{N}$ bond in the polymer chain have been previously synthesized. ${ }^{19}$ But methods to form carbon-nitrogen bond in aromatic systems are

${ }^{\dagger}$ To whom correspondence should be addressed.

limited to rather vigorous processes which are first copper mediated. ${ }^{20-21}$

Our interests in engineering thermoplastics have been directed toward the synthesis of amorphous, high molecular weight, soluble materials with high glass transition temperatures. In this paper, we describe three novel polymers from the dimethyl substituted phthalazinone monomers to improve these properties. These materials have high glass temperature and high thermooxidative stability. The polymers have good solubility in $\mathrm{CHCl}_{3}$ and several other solvents. This makes them possibly prepared thermally stable membranes. Also the presence of the branch methyl group could make the polymers functionized by chemical modification. ${ }^{22}$

\section{EXPERIMENTAL}

\section{Monomer Synthesis}

The preparation of the dimethyl substituted hydroxylphenyl phthalazinone was according to the ref 18 . After recrystallization from ethanol, we get the purified bisphenol, $\mathrm{mp} 281^{\circ} \mathrm{C} ;{ }^{1} \mathrm{H} \mathrm{NMR}$ (ppm) $\left(400 \mathrm{MHz} \mathrm{CDCl}_{3}\right)$ $12.55(\mathrm{~s}, 1 \mathrm{H}, \mathrm{NH}), 8.2-8.5(\mathrm{~m}, 2 \mathrm{H}, \mathrm{OH}$ and $8-\mathrm{H}), 7.7-$ 7.9 (m; 3H, 5-, 6-, 7-H), 7.15 (m; 2H, 2'-, 6'-H), 2.25 $\left(\mathrm{s} ; 6 \mathrm{H}, \mathrm{CH}_{3}\right)$; IR $\left(\mathrm{cm}^{-1}\right)$ 3380, 3170, 3040, 2951, 2905, $1654,1600,1499,1481,1464,1373,1241,1157,1030$, 688.

\section{Polymer Synthesis}

To a dry $100 \mathrm{ml}$ 3-neck flask equipped with a condenser, thermometer and nitrogen inlet, the phthalazinone monomer was added together with 1.0 eq of $4,4^{\prime}-$ dichlorodiphenylsulfone or 4,4'-difluorobenzophenone or both of them, $1.4 \mathrm{eq}$ anhydrous potassium carbonate, solvent to form a $30-35 \%$ solution, and chlorobenzene.

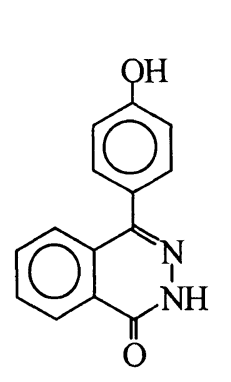

1

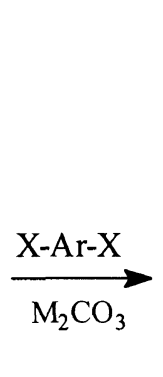

Scheme 1.

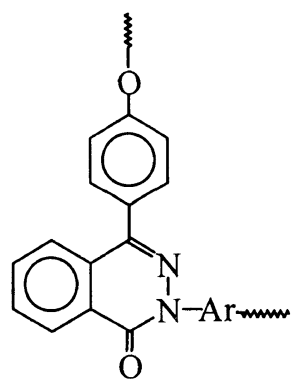

2 


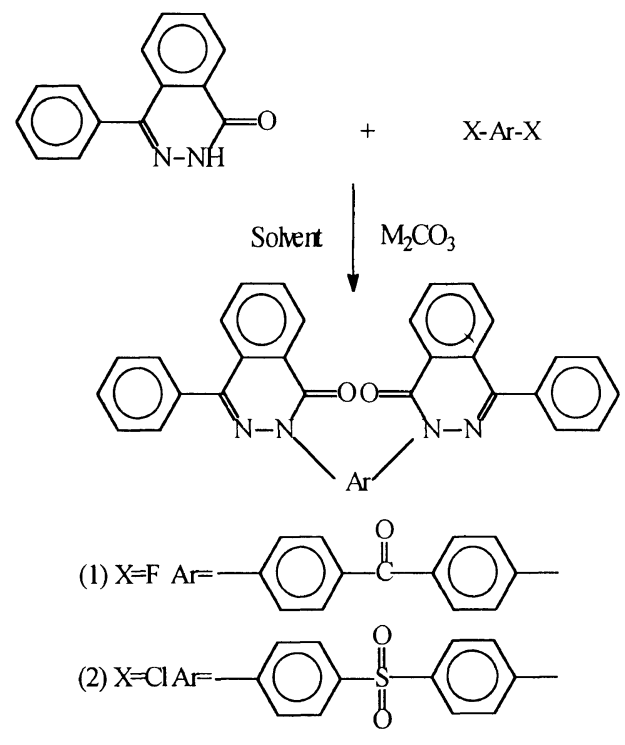

Scheme 2.

The mixture was heated to reflux by oil bath. After complete dehydration, it was increased to $150-250^{\circ} \mathrm{C}$. After maintaining the temperature for $4-18 \mathrm{~h}$, the reaction solution was diluted with solvent and poured into a blender containing ethanol while being well stirred. The polymers were filtered off and purified by dissolving in $\mathrm{CHCl}_{3}$, then precipitating in ethanol, after filtration, the polymers were dried in air and then in a vacuum oven at $70-80^{\circ} \mathrm{C}$ overnight.

\section{Model Reaction}

The phenyl phthalazinone was prepared according to the ref 4 and $5 . \mathrm{mp} 240^{\circ} \mathrm{C} ;{ }^{1} \mathrm{H}$ NMR $\left(90 \mathrm{MHz}, \mathrm{CDCl}_{3}\right)$ $12.75(\mathrm{~s}, 1 \mathrm{H}, \mathrm{NH}), 8.2-8.5(\mathrm{~m}, 1 \mathrm{H}, 8-\mathrm{H}), 7.5-7.95(\mathrm{~m}$, $8 \mathrm{H}, \mathrm{Ar}-\mathrm{H})$; IR ( $\left.\mathrm{cm}^{-1}\right) 3304,3158,3035,2943,2899,1670$, 1607, 1553, 1487, 1445, 1362, 1337, 1220, 1155, 975, 900, $791,751,701,685,603,544$. We use this phthalazinone as a phenol which reacted with the dichlorodiphenylsulfone or difluorodiphenyl-ketone such as Scheme 2. The reaction condition is the same as the polymerization. So we acquired two model compounds. The compound from the dichlorodiphenylsulfone, IR $\left(\mathrm{cm}^{-1}\right) 3064,1669$, $1588,1491,1445,1409,1323,1304,1181,1156,1131$, $1108,972,837,787,737,691,638$. The Compound from the difluorodiphenyl-ketone, IR $\left(\mathrm{cm}^{-1}\right), 3059,1672$, $1600,1445,1413,1318,1275,1132,973,932,785,764$, 689.

\section{RESULTS AND DISCUSSION}

After the bisphenol was recrystallized, purity was $99.5 \%$. Using this biphenol, we acquired the polymers by polymerization with dihalide monomers. The Properties of the polymers are shown in Table I. All the materials were prepared in dipolar apotic solvents. The reaction temperature is $150-250^{\circ} \mathrm{C}$ (If the $T$ is higher, the polymers have the possibility of insoluble part in the solvent). In this way, high molecular weight polymers were readily formed in $4-18 \mathrm{~h}$ and cast into good films. When the dichlorobenzophenone was used to prepare poly(phthalazinone ether ketone) (PPEK), we could not acquire high molecular weight material. Comparing these

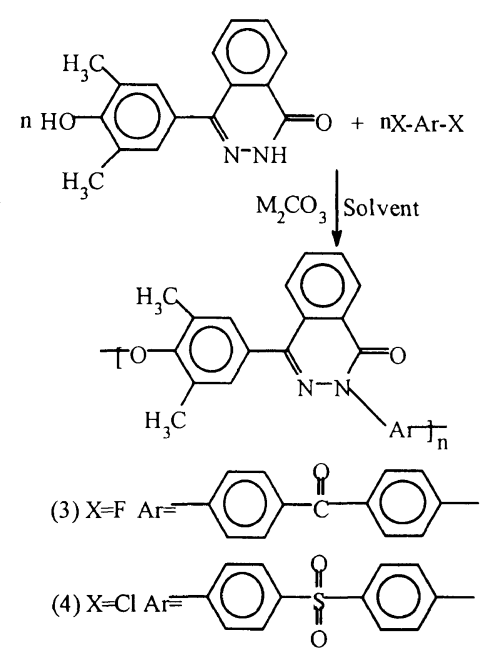

(5)X-Ar-X=(3) and (4) (3)/(4) $=1: 1$

Scheme 3.

Table I. Properties of the polymers

\begin{tabular}{cccc}
\hline Polymer & $\frac{\eta_{\text {inh }}{ }^{\mathrm{a}}}{\mathrm{dlg}^{-1}}$ & & $\frac{T_{\mathrm{g}}^{\mathrm{b}}}{\mathrm{TGA}^{\mathrm{c}}(5 \%)}$ \\
\cline { 2 - 4 } & 0.47 & ${ }^{\circ} \mathrm{C}$ & ${ }^{\circ} \mathrm{C}$ \\
\hline 3 & 0.41 & 295 & 421 \\
5 & 0.42 & 322 & 416 \\
\hline
\end{tabular}

${ }^{a}$ Measured at a concentration $0.5 \mathrm{~g} \mathrm{dL}^{-1}$ in $\mathrm{CHCl}_{3}$ at $25^{\circ} \mathrm{C}$. ${ }^{\mathrm{b}}$ From DSC measurement conducted at a heating rate of $10^{\circ} \mathrm{Cmin}^{-1}$ in nitrogen. ${ }^{\mathrm{c}}$ From TGA measurement conducted at a heating rate of $10^{\circ} \mathrm{C} \min ^{-1}$ in nitrogen.

experiment results, we found that an arylfluoride activated by a carbonyl group in the para position is much more reactive than an aryl chloride in aromatic nucleophilic substitution, also we found the dihalid activated by a sulfone group is more reactive than a carbonyl group.

The polymer poly(phthalazinone ether sulfone) (PPES) shows a $T_{\mathrm{g}}$ of $322.2^{\circ} \mathrm{C}$, and is soluble in polar aprotic solvents, such as $N$-methylpyrrolidone (NMP) and most chlorinated solvents such as chloroform, tetrachloroethane and chlorobenzene. Polymer PPEK and poly(phthalazine ether sulfone ketone) (PPESK) have $T_{\mathrm{g}} \mathrm{s}$ of around $300^{\circ} \mathrm{C}$, are respectively soluble in tetrachloroethane and chloroform at room temperature, which have glass temperatures $295^{\circ} \mathrm{C}$ and $309^{\circ} \mathrm{C}$. The improved solubility of these poly(aryl ether)s can be explained by the presence of both the flexible methyl groups and the bulky phthalazinone moieties which inhibit polymer crystallization and facilitate the penetration of solvent molecules between the polymer chains. The substituted methyl group and phthalazinone moieties also make these polymers have higher $T_{\mathrm{g}} \mathrm{s}$. The TGAs of the polymers show they have no weight loss around $400^{\circ} \mathrm{C}$. This shows these polymers have excellent thermal stability.

From the IR of the product of the model reaction (2), we could not find the peak of the $-\mathrm{O}$ - bond in 1200 $1250 \mathrm{~cm}^{-1}$, but could find the strong carbonyl group absorption at $1669 \mathrm{~cm}^{-1}$. From the IR of product of the model reaction (1), we could not find the $-\mathrm{O}$ - bond 
absorption either. This confirms that the model compounds were acquired by $\mathrm{N}-\mathrm{C}$ coupling reaction, not the phenol resonance structure of the phthalazinone by $\mathrm{O}-\mathrm{C}$ coupling reaction. From the model reaction, we could think the polymerization reaction is through $\mathrm{N}-\mathrm{C}$ coupling reaction when the side of phthalazinone react with the active dihalides. This could be also confirmed by the IR of the PPES (it shows the strong carbonyl group absorption).

In conclusion, this phthalazinone monomer could act as a bisphenol. It was reacted with activated aryl halides to give high molecular weight novel polymers in a onestep reaction involving the formation of $\mathrm{N}-\mathrm{C}$ bond. The formed polymers show high glass transition temperatures and good solubility. Further study of these polymers is in progress.

\section{REFERENCES}

1. H. Cherdron, F. Herold, and A. Schneller, Chem. Unserer Zeit, 23, 181 (1989).

2. H. Munstedt and H. Zeiner, Kunststoffe, 79, 993 (1989)

3. A. Lucke, Kunststoffe, 80, 1154 (1990).

4. F. Herold and A. Schneller, Adv. Mater., 4, 143 (1992).

5. T. E. Attwood, P. C. Dawson, J. L. Freemann, L. R. J. Hoy, J.
B. Rose, and P. A. Staniland, Polymer, 22, 1096 (1981).

6. M. J. Mullins and E. P. Woo, J. Macromol. Sci., Rev. Macromol. Chem. Phys., C27, 313 (1987).

7. P. M. Hergenrother, B. J. Jensen, and S. J. Havens, Polymer, 29, 358 (1988).

8. M. Ohno, T. Takata, and T. Endo, J. Polym. Sci. Part A, Polym. Chem., 33, 2647 (1995).

9. C. Tianlu, Chinese Patent, 85108751 (1985).

10. G. Qipeng, H. Jinyu, and C. Tianlu, J. Appl. Polym. Sci., 42, 2851 (1991).

11. J. Lee and C. S. Marvel, J. Polym. Sci. Part A, Polym. Chem., 22, 295 (1984)

12. C. K. Ober and T. L. Bluhm, Polym. Bull., 15, 223 (1986).

13. H. R. Kricheldorf and U. Delius, Macromol. Chem., Rapid Commun., 10, 41 (1989)

14. H. R. Kricheldorf and U. Delius, Macromol. Chem., 190, 1277 (1989).

15. W. Riss and D. Y. Sogah, Macromolecules, 23, 4029 (1990).

16. J. C. Lim, J. Kotani, M. Suzuki, and T. Saegusa, Macromolecules, 24, 2698 (1991)

17. Y. Gao and X. G. Jian, J. Dalian Univ. of Technol., 37, 547 (1997).

18. N. Berard and A. S. Hay, Polym. Prepr., 34, 148 (1993).

19. H. Ghassemi and A. S. Hay, Macromol. Chem., 26, 5824 (1993).

20. R. G. Bacon and A. Karim, J. Chem. Soc., Perkin Trans. 1, 272 (1972).

21. S. R. Stabler and Jahangir, Synth. Commun., 24, 123 (1994).

22. F. Wang and J. Rowers, J. Polym. Sci. Part A, Polym. Chem., 32, 2413 (1994). 